Archivum, LXX (I), 2020, pp. 17-41

\title{
Mundos pos-imposibles. Una aproximación a la ciencia ficción rara
}

\author{
Claudia Sofía Benito Temprano \\ Universidad Autónoma de Madrid \\ claudia.benito@uam.es
}

Recibido: 20/06/2019

Aceptado: 29/10/2019

\section{RESUMEN:}

En el presente artículo se propone la lectura de tres obras de ciencia ficción: ¡Tierra!, de Stefano Benni, La guía del autoestopista galáctico, de Douglas Adams, y El hombre en el castillo, de Philip K. Dick. Partiendo de la formulación teórica de los 'mundos imposibles', se explicará el efecto desautomatizador de estas ficciones, que llevan al lector a un estado psicológico cercano al de lo 'raro' descrito por Fisher. Se expondrá el modo en que los autores insertan en los niveles estructural y semántico del texto elementos extraños e inesperados para provocar la incomprensión externa (del universo ficcional) y suscitar la revisión del propio sistema de conocimiento del lector (su percepción del universo actual). Será necesario un acercamiento al modo que tenemos de entender el quehacer científico, distinguiendo entre concepciones expertas y legas, para poder comprender en mayor profundidad la manera en la que está estructurado nuestro mundo actual.

PALABRAS CLAVE: mundos imposibles, raro, ciencia ficción, universos simbólicos. 
Pos-impossible worlds. An approach to weird science-fiction

\begin{abstract}
:
The present article proposes the reading of three science-fiction works: Stefano Benni's Terra!, Douglas Adams's The Hitchhiker's Guide to the Galaxy and Philip K. Dick's The Man in the High Castle. Drawing from the theoretical concept of 'impossible worlds' we aim to explain the deautomatizing effect of these fictions, which leads the reader to a psychological state akin to Fisher's 'weirdness'. With this perspective, we will explore the way in which the authors introduce unusual elements in the structural and semantic levels of the text to provoke in the audience an external incomprehension of the fictional universe and, thus, the inner evaluation of their cognoscitive system. In order to gain a deeper comprehension of how the actual world is structured, it shall be required to approach how we understand scientific endeavour, drawing a distinction between expert and non-expert conceptions.
\end{abstract}

KEY WORDS: impossible worlds, weird, science-fiction, symbolic universes.

Confieso humildemente que no poseo capacidad alguna para resolver tales problemas; mi mente es euclidiana, terrena. ¿Cómo resolver lo que no es de este mundo? A ti también te aconsejo no pensar nunca en esto, amigo Aliosha, sobre todo en lo de si Dios existe o no existe. Todas estas cuestiones escapan por completo a la mente creada por el mero concepto de las tres dimensiones.

Fiódor Dostoievski, Los hermanos Karamázov $(2001,384)$

Existe un tipo de ficciones que llevan a replantearse los límites de la realidad. Transcurren en lo que autores como Eco (1979) Martín Jiménez (2015a; 2015b) o Rodríguez Pequeño (1997) han llamado mundos 'imposibles'. Estos se distinguirían del mundo actual, que es aquel en el que vivimos, caracterizado por la necesidad lógica, y de los mundos posibles, constituidos por alternativas al modo en que efectivamente son las cosas. ${ }^{1}$ Dentro de esta tipología hay una clase específica de narraciones posmodernas

1 Al hablar, en este artículo, de mundo 'actual' y mundos 'posibles', 'ficcionales' o 'literarios', estaremos haciendo alusión a la teoría de los mundos posibles en su aplicación a la teoría literaria (Ryan, 1991). 
que podrían clasificarse como ciencia ficción: son estas las que trataremos en este artículo.

Uno de esos mundos imposibles es el de la novela ucrónica de Philip K. Dick, El hombre en el castillo (1962), que describe cómo es la vida de los habitantes de un mundo en el que las Potencias del Eje han ganado la Segunda Guerra Mundial. En el texto se desarrolla una reflexión política, social y económica, pero aquí nos interesa especialmente el quehacer de un escritor subversivo en ese mundo, Hawthorn Abdensen (el "hombre en el castillo" que da nombre a la ucronía), que ha publicado un librito en el que imagina cómo sería el planeta si el bando vencedor hubiese sido la Alianza. O lo que es lo mismo, un novelista (ficcional) que presenta un mundo posible (ficcional) inmensamente similar a nuestro mundo actual.

En otras palabras, tenemos a un escritor escribiendo a un escritor, que supuestamente escribe a ese escritor: la estructura de la "cinta de Moebius" escheriana a la que alude Rodríguez Pequeño en el artículo citado. A esto hay que sumar que Dick contó en algún momento cómo se había valido del I Ching para construir la narración de su novela (Mountfort, 2016; Carrère, 2018). El libro chino de las predicciones no solo es un mecanismo creativo, un elemento extratextual, sino que es además un artilugio muy utilizado por los personajes de El hombre en el castillo. Tan utilizado que el mismísimo Hawthorn Abdensen estructura el argumento de su novela consultándolo. De nuevo tenemos una cierta autorreferencialidad: el autor utiliza un método creativo para construir al autor' de la historia', que emplea ese mismo método creativo para escribir la Historia.

- Hawth [Hawthorn] fue armando el libro pedazo a pedazo en miles de consultas, por medio de las líneas. Período histórico, tema, caracteres, argumento. Le llevó años. Hawth llegó a preguntarle al oráculo si el libro tendría éxito, y el oráculo le contestó que sería un gran éxito, el primero de su carrera. Lo que usted dice es cierto; y tiene que haber consultado mucho el oráculo, para averiguarlo. 
- Me pregunto qué razones llevaron al oráculo a escribir una novela. ¿Pensó en preguntárselo? Y eso de que los japoneses y alemanes perdieron la guerra. ¿Por qué esa historia particular y no alguna otra? ¿Por qué no puede decirlo directamente, como de costumbre? Esto tiene que ser distinto, ¿no creen? (Dick, 1994, 266-267)

A través de la metalepsis ficcional, que mezcla la existencia de los personajes con la realidad heterodiegética de autor y lectores (Martín Jiménez, 2015a, 17), lo que entra en cuestión ya no es solo la indistinción entre mundo posible y mundo actual - Dick hace a sus personajes conscientes de la 'irrealidad' del mundo que habitan, ratificando el estatus de realidad del mundo de sus lectores - sino cuáles son las leyes que rigen el mundo actual. El personaje está redactando una suerte de cosmogonía que existe, es real, pero no es actual: a la hora de la verdad ese personaje no escribe nuestro mundo, sino un mundo salido de su imaginación, es decir, otro submundo ficcional más que el lector asimila al mundo actual (Eco, 1979). Sin embargo, la percepción final del receptor es que el mundo actual está escrito por un personaje de una novela inscrito en un mundo literario, que está escrito por un autor del mundo actual. ¿Cuál es más real de los dos, el mundo literario o el actual? ¿Y está nuestra existencia regida por las normas de la física o por las del I Ching?

Esta sensación de incertidumbre en el lector aumenta, también, gracias al modo en que reaccionan los protagonistas de la novela al descubrir que el pasado y el presente que ellos conocen, el hilo temporal que habitan, no son lo que realmente sucedió. El conocimiento de la realidad no cambia nada para ellos, a efectos prácticos: saber que su existencia es solo una alternativa a la de otros altera el modo en que perciben su entorno, pero no la manera de la que interaccionan con él:

-Oráculo - dijo Juliana-, ¿por qué escribiste La langosta se ha posado? ¿Qué quisiste que supiéramos?

-Tiene una manera de presentar la pregunta que es de veras 
supersticiosa; me desconcierta usted - dijo Hawthorne, pero ya se había sentado en cuclillas para observar el tiro de las monedas-. Adelante - dijo, y le pasó a Juliana tres monedas chinas de bronce agujereadas en el centro-. Son las que uso yo generalmente.

Juliana empezó a tirar las monedas; se sentía tranquila y confiada. Hawthorne iba trazando las líneas. Luego del sexto tiro Hawthorne miró el papel y dijo:

-Sun arriba, Tui abajo, Vacío en el centro.

$-¿$ Conoce usted el hexagrama? - dijo Juliana -. ¿Lo recuerda sin recurrir al libro?

-Sí - dijo Hawthorne.

-Es Chung Fu - dijo Juliana - . La Verdad Interior. Yo también lo recuerdo sin el libro. Y sé lo que significa.

Alzando la cabeza, Hawthorne observó a Juliana un rato. Tenía ahora una expresión casi salvaje en la cara. - Significa que mi libro dice la verdad, ¿no es cierto?

-Sí - dijo Juliana.

Había cólera en la voz de Hawthorne: - ¿Alemania y Japón perdieron la guerra?

-Sí. [...] - La verdad, pensó, tan terrible como la muerte, pero más difícil de encontrar. Había sido afortunada. (Dick, 1994, 268270)

El dibujo de Escher nos puede servir para ilustrar el funcionamiento, además de los mundos imposibles, de los mundos 'pos-imposibles': aquellos que comienzan siendo ficciones corrientes para irse deformando hacia lo imposible. Imaginemos la famosa mano dibujando una mano que a su vez la dibuja, etc. Pero ahora imaginemos que la primera mano, a mitad del dibujo, fuese 'recortando' o 'modelando' la mano que dibuja, cambiando la forma de representarla. Tendríamos una mano recortando una mano que, de pronto, ya no sabemos, dibuja, o recorta, la mano original. La mano del autor real, dibujando la mano del autor inventado, empieza a jugar con ella, va alterando la percepción y la imagen realista que nos habíamos prefigurado. Actúa más 
rápido que nosotros, que ya nos hemos asentado en un género, y no nos da tiempo a calcular de nuevo el horizonte de expectativas desde el que tendremos que mirar la nueva mano inventada. Por un momento nos será imposible pensar la mano del autor real como era en un origen: la veremos deformada, como su dibujo. Al igual que ocurre en el símil anterior, en estos textos hay una torsión que causa que nuestra percepción vaya cambiando a medida que leemos: no estamos hablando de un tipo de mundos que se configuren estáticamente como continuos, sino de una forma de concebir ambos mundos posibles que varía, que muta a lo largo de la lectura del texto. Durante la lectura de El hombre en el castillo, por ejemplo, habíamos tenido la conciencia de estar leyendo un texto ficcional, bastante tradicional, en el cual en algún punto Dick se permitía la licencia de hacer viajar a sus personajes entre realidades paralelas. Habíamos suspendido nuestra incredulidad sin abandonar esta conciencia de estar leyendo una ficción, sabiendo que todas las verdades que admitiésemos lo eran únicamente en la ficción. Solo cuando llegamos al final de la obra vemos este giro que cuestiona todas las asunciones que habíamos hecho previamente.

Es obvio que este engaño visual solo sucede mientras leemos. En ese 'viaje ontológico' que tiene lugar cuando nos sumergimos en una ficción, y en el que de pronto dejamos nuestra existencia en suspenso para pasar a vivir las cosas 'como si' lo que sucede en el texto literario fuese real. Ahora bien, uno de los efectos que pueden provocar los mundos pos-imposibles sobreviene, para el receptor inmerso en el pacto ficcional (o en el ingenuo), incluso después de la lectura: y es que no es inhabitual que tras cerrar el libro, en el momento de irnos a dormir, dediquemos un instante a preguntarnos por qué no nos resulta descabellado imaginar que esa decisión nuestra de irnos a dormir no sea tal decisión, sino un destino prescrito por los palillitos de un ente superior que juega al I Ching. ${ }^{2}$

2 La obra de Dick, como el resto de textos de los que hablaré aquí, nos hacen pensar acerca de la realidad del objeto y su representación. El famoso "a rose is a 
En 1986, Stefano Benni escribe una obra paródica de ciencia ficción en la que el mundo, después de la Cuarta Guerra Mundial, se encuentra dañado por múltiples problemas ambientales. Por suerte, un náufrago ha localizado un planeta en el universo con características muy similares a las del nuestro, y un grupo de especialistas de diversos ámbitos se embarca en una nave para tratar de encontrar otra vez el planeta habitable. Cuando al fin llegan a él, descubren que ese nuevo planeta es la Tierra, y consiguen hacer llegar a sus coetáneos la información de que toda la energía que precisan está contenida en las pirámides incas - construidas por ellos y accesibles gracias a una profecía del I Ching-, donde por efecto de algún tipo de magia se ha concentrado la luz solar.

Lo que nos interesa de esta novela es que cuestiona directamente el poder explicativo de la ciencia. Dos de sus personajes principales, el telépata asiático Fang y el clon superdotado Einstein, se embarcan en discusiones frecuentes con respecto a lo que otorga superioridad a la ciencia por encima de otras creencias. Fang, como Hawthorn Abdensen, es un fanático del I Ching, mientras que Einstein cree que el funcionamiento del universo está regido por lo que generalmente llamamos 'leyes de la física'. $\mathrm{Al}$ final, lo que ocurre en nuestro mundo solo puede explicarse por medio de una combinación entre el I Ching y las creencias del pueblo Inca. En esta obra no es solo la estructura del mundo ficcional (bastante anómalo, dado el propio estilo de la obra, por otro lado) lo que suscita ese cuestionamiento de nuestra fe en la ciencia, sino las argumentaciones de Fang y Einstein:

rose is a rose" de Stein es reinterpretable a la vista de estas lecturas como "a rose is a rose, why is it a 'rose'?". Se establece una distinción entre la extensión, el signo y la intensión: la rosa prototípica, ese palo con pinchos y pétalos rojos que todos conocemos, al cual alguien le ha impuesto el nombre de 'rosa', y que científicamente se denomina 'rosa', de la tribu roseae de las rosoideae del orden de los 'rosales' y de la clase Magnoliophyta, quizás sea capaz de traicionar nuestras expectativas en el mundo actual, llevando a cabo un movimiento impropio de una rosa. Entonces, ¿no tendremos que replantearnos toda la categoría de las Magnoliophyta, y la de las plantas, y la de...? El problema literario desemboca en un conflicto ontológico y epistemológico. 
- Voy a terminar los planes de vuelo. He previsto que llegarán a Meskorska en treinta y dos días.

- También yo estaba haciendo previsiones — dijo Fang - , con el I Ching.

- ¿Ese jueguecito chino de adivinación? - preguntó sorprendido Einstein.

-Jueguecito, lo llama - dijo Fang sonriendo-. ¿Prever los cambios solo es eso para usted? ¿No es también observación, intuición, interpretación? Para nosotros la palabra 'suan' quiere decir tanto cálculo aritmético como adivinación. ¿No podría ser que estos hexagramas tuvieran la misma confirmabilidad que tantas supuestas verdades científicas?

-Oh, no lo sé, en cualquier caso es un método que no me interesa. Yo soy un científico occidental.

-Y en occidente y en oriente vemos estrellas diferentes, pero, ¿acaso no es el mismo cielo? Fue, sin embargo, un occidental, si no recuerdo mal, un tal Ptolomeo, quien escribió el Almagesto, un tratado de astronomía, y el Tetrabilos [sic], que es un texto fundamental de astrología.

- Es posible que haya entendido adónde quiere llegar - suspiró Einstein - , ciencia y misterio, ciencia y filosofía, la microfísica de las partículas y el yin y el yang, la agitación subatómica y la danza de Shiva, el tao y el teorema de Bell. Luego se acaba por meter a Nostradamus en el ordenador, hacer el horóscopo a los gatos y buscar monstruos en los lagos durante el picnic. Conozco las ideas de estos pseudocientíficos o parafilósofos tan de moda. Los diarios están llenos de sus descubrimientos. ¿Quiere sus nombres?

-Espere, intentaré adivinarlos. ¿Demócrito? ¿Pitágoras? ¿Heráclito? ¿Aristóteles? ¿Llevan tal vez una sección en el Times?

[...]

- Señor Fang - dijo Einstein, impaciente-, creo que podríamos seguir discutiendo hasta el infinito: usted atribuirá este equilibro al Amor o al Odio Empedócleo, o al yin y al yang, y yo hablaré de equilibrio entre fuerza gravitacional y fuerza magnética. ¿No cree? 
-Yo creo que, sin embargo, llegará un momento en que se verá obligado a admitir que ya no consigue explicar nada. Porque el equilibrio de la ciencia camina sobre un delgado puente de descubrimientos, colgado sobre un precipicio de oscuridad. (Benni, 1986, 58-59) ${ }^{3}$

Algo semejante sucede en la tetralogía iniciada cuatro años antes por Douglas Adams, también construida como una parodia de la ciencia ficción. Argumentos que prueban la posibilidad de conocer un determinado evento se convierten en argumentos de la existencia de tal evento; en este sentido, el texto disloca el orden tradicional de las narraciones de ficción científica: el autor crea un mundo plagado de irregularidades lógicas de todo tipo, que somos capaces de asimilar gradualmente, porque de pronto, después de haber sucedido, nos son explicadas. Por ejemplo: aparece azarosamente y de la nada una ballena en el cielo; esto es físicamente imposible, pero varios capítulos después de que suceda, cuando nosotros nos hemos visto obligados a continuar la lectura obviando esta incoherencia, alguien nos explica que la aparición se debe al uso de la energía de la improbabilidad. En este caso, es la ridiculización de los intentos humanos por buscar 'verdades' lo que acaba suscitando en el lector una especie de malestar divertido, acostumbrándole a admitir que no todo tiene por qué aportar significado a una narrativa total.

Junto a este mecanismo textual encontramos otros: lo que ocurre en el universo de Douglas Adams está recogido en una enorme guía para autoestopistas galácticos escrita por expertos viajeros. En algunos momentos parece, sin embargo, que esa misma guía es la que determina lo que existe en el universo ficcional, aunque no se llega a especificar. Hay aquí un comentario

3 En este caso, son los propios personajes los que nos dicen que, "maybe a rose is not a 'rose'", planteando que existe una distancia entre la realidad y las explicaciones o interpretaciones que construimos a partir de ella. Se establece una diferencia epistemológica que distingue la realidad de sus percepciones, y a través de una reformulación del diálogo platónico, Benni inserta la duda en la explicación mayoritariamente aceptable - la científica-. 
que llama nuestra atención sobre el modo en que construimos el saber en las sociedades contemporáneas: nos fijamos en aspectos que consideramos intrínsecos del mundo actual y los analizamos, describimos, y explicamos. Pero, por el camino, puede llegar un momento en que nuestras explicaciones estén deformando la manera en que vemos el mundo.

Evidentemente, los mundos de estos textos ficcionales tienen un estatuto ontológico diferente al del mundo actual, por la propia definición que solemos hacer del término 'ficción'. Del mismo modo, los mundos encerrados en los relatos que leen los personajes de esos mundos imposibles deberían estar en un orden ontológico inferior al de los mundos ficcionales. La particularidad de El hombre en el castillo era que por medio de diversas estrategias narrativas se generaba una ambigüedad ontológica que impedía distinguir entre el nivel-de-la-ficción y el nivel-de-laficción-dentro-de-la-ficción - el mundo ficcional del submundo ficcional - , y esto tenía como efecto la percepción, por parte del lector, de una continuidad entre ambos. Además, por asemejarse este submundo ficcional al mundo actual, la continuidad abarcaba también nuestro propio mundo. En cierto sentido, esto ocurre también con los mundos pos-imposibles, solo que en estos lo que acaba resultando confuso no es tanto el límite presentido entre ficción y realidad como la validez de los mecanismos epistemológicos empleados para abordar la explicación de ambas.

Las tres obras que venimos comentando, como habrá podido apreciarse, tienen ciertas características comunes. Muestran mundos que, aunque no lo son, 'podrían ser' el nuestro. Mundos con unos rasgos que les acercan más a lo que percibiríamos como una ficción realista que otros (Ryan, 1991, 34): mundos, en definitiva, más "verosímiles" que otros (Rodríguez Pequeño, 2008). En el caso de la ucronía de Dick, esas características se mantienen hasta que se descubre que realmente el mundo de referencia textual es un mundo construido solo sobre el papel. La ucronía es por su propia naturaleza una novela "histórica", en el sentido en que expone Eco (1988), pero cronológicamente incompatible con 
nuestro mundo. Sin entrar demasiado en su adscripción genérica, podríamos decir que es una ucronía fantástico-realista, prospectiva, o (y esto quizás es más discutible) de ciencia ficción. En todo caso, lo que importa en el presente artículo es que el mundo que describe no suscita ningún tipo de sospecha lógica en el lector, en principio, porque el pacto ficcional exigido no le hace pensar en ningún momento que se encuentre ante un universo fantástico. El hecho de que mantenga unas propiedades físicas, lógicas y de inventario idénticas a las del mundo actual nos hace percibirlo como un calco del mismo.

Las otras dos, ¡Tierra! y La guía del autoestopista galáctico, plantean más problemas. Son obras editadas - al menos en el mundo hispánico - dentro de colecciones de ciencia ficción, y no cuestionaremos aquí su adscripción genérica. Además, se inscriben dentro de una de las convenciones tradicionalmente identificadas con la ciencia ficción, ya que nos muestran una evolución posible de nuestro mundo futuro. Nuestra capacidad para aceptar que sucedan determinados hechos que subvierten los principios físicos del universo que habitamos en ese futuro ficcional tiene que ver con la mediación de una serie de inventos y descubrimientos, explicados por los personajes o descritos como si se aportaran pruebas de su existencia y funcionamiento. Ese futuro 'de mentira' que aparece en las obras de Benni y Adams nos resulta razonable porque entra dentro de lo que cabe esperar del desarrollo del conocimiento científico-técnico. Y nos lo podríamos llegar a creer porque parece estar respaldado por nuestro conocimiento científico y ser compatible con él. Siguiendo la definición de Suvin (1984), una de las más aceptadas para la ciencia ficción, se trata de obras que tienen como fundamento el "extrañamiento cognitivo", es decir, que plantean una innovación en el conocimiento (un conocimiento fundamentado en las bases epistemológicas imperantes en el presente) como punto de partida de las diferencias entre ambos mundos: el presente y el futuro. ${ }^{4}$

4 En ellas, el punto de partida sería algo así como que "a rose is something else than your 'rose' because we know more about roses than you. Thus, roses might have 
A este respecto se hace preciso esclarecer de qué hablamos cuando utilizamos expresiones como 'nuestro conocimiento científico'. En el mundo actual, hay un grupo de personas o instituciones con cierta autoridad para hablar de Ciencia, que saben qué entra bajo esta descripción. Incluso entre ellos hay polémica y discusión, pero en general venimos aceptando la existencia de un algo que es la Ciencia y que contribuye al conocimiento humano del mundo, y que ese algo tiene como consecuencia la continua evolución de una técnica que facilita la vida del hombre. Como constructo ideal, la Ciencia es algo objetivo; la palabra 'ciencia' tiene una intensión, va acompañada de un concepto. Pero también tiene una extensión: significa algo, es decir, los hablantes pueden nombrar distintas realidades o actividades como 'ciencia'.

En un texto titulado "El significado de 'significado"“ (1984), Putnam propone el experimento de la Tierra Gemela, que consiste en imaginar un mundo posible idéntico al nuestro en todo excepto por el hecho de que 'agua' no designa allí el compuesto químico $\mathrm{H} 2 \mathrm{O}$, sino el XYZ. Con este experimento mental, Putnam lo que quiere es defender la tesis de que el significado tiene existencia fuera de la mente de los hablantes. Imaginemos que en esa Tierra Gemela, exactamente igual a la nuestra, tenemos incluso un Doppelgänger. El agua, en ambas Tierras, tiene el mismo aspecto, sabor, textura... es un líquido indistinguible, en apariencia. Y tanto nosotros como nuestro Doppelgänger tenemos una representación idéntica del concepto 'agua'. Sin embargo, el objeto que designa el mismo es distinto en ambos casos. Para Putnam, esto demuestra que el significado no equivale a la representación mental que tenemos de un concepto: el significado es objetivo y, aun si no conociésemos la diferencia química entre ambos compuestos, la

changed, but your knowledge of what roses are is not completely wrong". Por poner un ejemplo: el estudio de las rosas y la mediación de la técnica en ese futuro ficcional quizás haya permitido a los humanos establecer la comunicación con ellas y descubrir que, bajo el sistema nervioso de las plantas, reside algún tipo de alma racional. Las rosas siguen siendo las mismas, y lo único que ha cambiado es el nivel de desarrollo científico de la humanidad, que ha permitido ampliar el significado del término 'rosa' al ahondar en el estudio de este ser vivo y descubrir nuevas características del mismo. 
palabra 'agua' estaría designando distintas realidades en la Tierra y en la Tierra Gemela.

Traemos al contexto de este artículo el experimento de Putnam para subrayar algunos aspectos de nuestra concepción de lo que es la ciencia que pueden resultar útiles para comprender la relación de los lectores con la ciencia ficción, sin suscribir necesariamente las conclusiones de este autor. Como hemos dicho, para los hablantes de las distintas Tierras es posible llamar agua tanto a $\mathrm{H} 2 \mathrm{O}$ como a $\mathrm{XYZ}$ sin entrar en conflicto, pero no podremos evitar que una minoría (los químicos) se pongan nerviosos, porque ellos saben que el agua no designa la misma cosa. ${ }^{5}$ Lo mismo sucede cuando utilizamos la palabra 'ciencia' para referirnos al conjunto de saberes y actividades que se incluyen en los productos de la ciencia ficción. Podemos decir que el 'extrañamiento cognitivo' de las obras que se agrupan dentro del género tiene base 'científica' tan solo según el significado social que le damos a la palabra 'ciencia' los individuos que no somos expertos en la materia. Todas las teorías y situaciones que nosotros identificaríamos como 'relativas a la ciencia' aceptando un grado de ficción limítrofe con el horizonte de acontecimientos que, admitimos, se podrían derivar de nuestra situación actual, nos permiten captar un grado alto de verosimilitud en las obras pertenecientes al género. Posiblemente físicos, químicos y matemáticos encuentren una cantidad ingente de errores e incongruencias en los textos de anticipación científica, y posiblemente esa situación sea la que ha llevado muchas veces a cuestionar la adecuación del término 'ciencia ficción'.

5 Yendo a un extremo mucho más extremo, imaginemos que un amigo botánico nos regala una planta con flores. Nosotros las observamos: tienen cinco pétalos amarillentos y un centro oscuro, lleno de estambres. Si nuestro amigo nos dice "he comprado estas rosas para ti", seguramente le miraremos con extrañeza. No son para nada esas flores repolludas y elegantes que todos tenemos en mente. Sin embargo, nos aclara nuestro amigo, la 'rosa pérsica' es, también, una 'rosa'. Luego mi 'rosa' y la 'rosa' de mi amigo, experto en botánica, no son lo mismo - lo que no quita para que la 'rosa' de él sea mucho más ajustada a la definición preestablecida que la mía, que incluso permite la entrada a las peonias-. 
Luego esta no-Ciencia (o no-ciencia-de-expertos) de la ciencia ficción, añadida a la coincidencia de personajes y eventos históricos del mundo ficcional con personajes del nuestro y sometidos a una dislocación temporal, empujados a pasados o futuros razonables, nos permiten 'creernos' de alguna manera un universo narrativo. Paradójicamente, en las novelas que estamos tratando, la ciencia, producto de la fantasía del autor, pretende levantar dudas sobre los fundamentos de la ciencia real, es decir, la que suponemos que tiene fundamento. La ciencia-que-no-esrealmente-ciencia se utiliza como mecanismo para hacernos dudar de la ciencia.

Tanto ¡Tierra! como La guía del autoestopista galáctico tienen un comienzo perfectamente verosímil, desde el punto de vista, digamos, científico. La falta de recursos en el planeta y la necesidad de emigrar, en una, y la aparición de una nave espacial en la otra, son muy características del género narrativo. Ahora bien, a medida que avanzamos en ambos textos nos vamos encontrando con elementos ajenos a la convención. El término 'raro', tal y como lo entiende Fisher, es perfectamente aplicable para explicar la sensación que va surgiendo de la lectura. Lo 'raro' para este autor es, en el seno de lo literario, "aquello que no debería estar allí" (2016, 12) y que produce una sensación estética inversa a lo ominoso freudiano permitiéndonos aproximarnos a lo interior desde el posicionamiento exterior. Desde cierto punto de vista, como el propio Fisher expone, podría interpretarse que toda obra de ciencia ficción es inherentemente 'rara', en la medida en que el género se fundamenta en el extrañamiento cognitivo y en la inclusión de un novum, como ya anticipara Suvin (1984). Pero, dando por hecho que, en tanto que convención literaria, este principio está ya fuertemente asentado, es posible afirmar que todas las obras incluidas en el ámbito de la ciencia ficción, al pertenecer a un género asentado, no provocan el sentimiento que Fisher asocia a lo 'raro'.

En las obras de Benni y Adams, sin embargo, nos encontramos con aspectos que eluden las convenciones del género. La irrupción de incongruencias, elementos inverosímiles, aspectos 
propios de la parodia y juegos lingüísticos desvían, poco a poco, la sustitución de lo maravilloso científico por lo fantástico (Todorov, 1981), pero no en un plano estructural, sino del mismo modo en que lo fantástico irrumpe en la estética posmoderna: a través del lenguaje. Por medio del juego de palabras, Adams permite contemplar un mundo un poco menos racional. "Let us say, then, that the mysteries of these texts are mysteries of language, not of their fictional worlds" (McHale, 2004, 81):

- Has dicho que tuviste la sensación de que la Tierra había estallado... realmente...

-Sí. Más que una sensación.

- ¿Que es lo que todo el mundo atribuye - preguntó, indeciso- - a alucinaciones?

-Sí. Pero eso es ridículo, Arthur. La gente cree que con decir "alucinaciones" queda todo explicado y, al final, lo que uno no entiende es que no existe. No es más que una palabra, no explica nada. No explica por qué desaparecieron los delfines. (Adams, 1988, 95) ${ }^{6}$

6 Lo 'raro' resulta sorprendente, y, en las novelas de las que hablamos, conlleva la incursión de una sensación de acientificidad en lo inicialmente 'científico'. Volviendo a la metáfora botánica que venimos utilizando como ejemplo, encontraríamos un ejemplo más o menos efectivo del funcionamiento de este mecanismo en el siguiente fragmento de los Diarios de las estrellas de Stanislaw Lem:

[L]as sabanas de Beluria están todas irisadas de variopintas flores, entre las cuales destaca una rosa de color rojo oscuro, de extraordinaria belleza y exquisito aroma (rosa mendátrix Tichiana, como tuvo la amabilidad de llamarla el profesor Pingle por ser yo el primero en describirla). La supuesta flor, es de hecho, una excrecencia en la cola del vendalino, una fiera carnívora beluriana. El vendalino hambriento se oculta entre la maleza y extiende su larguísima cola, de modo que solo la flor sea visible en la hierba. Sin sospechar nada, el turista se acerca para aspirar su aroma y entonces el monstruo se le echa encima por detrás. Sus colmillos son casi tan largos como los de un elefante. ¡He aquí cómo se comprueba la variante cósmica del adagio que dice que no hay rosa sin espinas! $(1978,274)$.

En merced a la representación prototípica de la rosa que todos invocamos, el escritor polaco hace a su protagonista descubridor de una nueva especie floral. El descubrimiento per se podría resultar verosímil, si tenemos en cuenta que el prota- 
La combinación de elementos pertenecientes a géneros que, desde el punto de vista teórico, no son compatibles, evoca un tipo de 'rareza', según Fischer, debido a la percepción de "su ausencia de familiaridad, su combinación de elementos previamente concebidos como inconmensurables, su compresión, los desafíos que plantea a los modelos corrientes de legibilidad" $(2016,42)$. El reto de establecer si la obra entra dentro del paradigma fantástico o el científico ficcional es y, simultáneamente, no es una de las constantes que guían la lectura, al igual que ocurre en otras ficciones actuales como The Leftovers (2014-2017). El planteamiento de las obras tratadas no aborda solo la cuestión referente a las limitaciones del conocimiento humano, sino que llega a suscitar en el lector preguntas referentes a la construcción de la realidad, como es propio de los textos posmodernos (McHale, 2004).

Una de las lecturas que se puede hacer de las obras citadas parte de este concepto de 'inconmensurabilidad', que alude a la imposibilidad de comparar dos teorías científicas o paradigmas (Kuhn, 1988) cuando estas utilizan lenguajes distintos (Feyerabend, 1984). La imposibilidad de explicar por qué la teoría del Big Bang es más verdadera que, por ejemplo, la del Génesis o que la propuesta por Adams según la cual la Tierra es un macrocomputador destinado a plantear la pregunta fundamental para el sentido de la vida, respondida ya de antemano por otro macrocomputador con un escueto " 43 ". Aunque hay que aclarar que, posiblemente, la adscripción de los autores de estas ficciones

gonista de la obra de Lem, Ijon Tichy, vive en un futuro posterior a la colonización de la galaxia, y está hablándonos del planeta Beluria. Ahora bien, seguimos leyendo y la rosa, científicamente categorizada como 'rosa' por el profesor Pingle, no es en realidad una flor. Nuestra credibilidad queda suspendida, el pacto es traicionado, y esa rosa ya no es una 'rosa', aunque externamente se parezca a una rosa y haya sido de hecho clasificada como tal. Esto solo es comprensible si aceptamos que muchas de las narraciones que conforman los Viajes y Memorias escritos por Lem son obras de ciencia ficción raras, que transcurren en mundos pos-imposibles en los que una rosa es a la vez una rosa y no lo es, es decir, mundos en los cuales una misma proposición lógica es y no es verdadera. 
al anarquismo epistemológico no persigue la misma meta que animaba a Feyerabend.

Una obra como La guía del autoestopista galáctico es susceptible de ser leída como una reflexión con respecto a las distintas funciones de la ciencia (que explica cómo es el mundo) y la fe (que trata de dar un sentido a esa explicación), o un intento de desmitificar las dos, ciencia y fe. Esta interpretación encuentra respaldo en otros textos de Adams, en los cuales manifiesta la necesidad de compatibilizar ambos aspectos:

As we become more and more scientifically literate, it's worth remembering that the fictions with which we previously populated our world may have some function that it's worth trying to understand and preserve the essential components of, rather than throwing out the baby with the bath water; because even though we may not accept the reasons given for them being here in the first place, it may well be that there are good practical reasons for them, or something like them, to be there. $(2003,147)$

Por otro lado, en jTierra! estamos más bien ante una reflexión bioética, que critica la constante lucha internacional por el control de fuentes de energía y avances tecnológicos. En todo caso, la finalidad perseguida por los autores de las obras que tratamos tampoco es decisiva de cara a la comprensión que hagamos los lectores del texto, ya que, volviendo a esa formulación teórica que se construye a partir de la 'metáfora' de los mundos posibles, Todorov (2012) incluye una matización: el universo imaginario construido por el autor no tiene por qué ser igual al que construye el lector, al fin y al cabo, junto a los referentes textuales significados hay otros 'simbolizados', susceptibles de interpretaciones múltiples.

La configuración rara de este universo imaginario ficcional en las obras analizadas nos hace replantearnos el modo en que entendemos el universo real. $\mathrm{O}$, mejor dicho, la manera en que construimos este entendimiento del universo real. La semióloga Julia 
Kristeva compara las distintas concepciones de la 'ciencia' en la actualidad con la discusión que tuvo lugar en la universidad medieval acerca de los universales. Al hilo de esta comparación entre el presente y el pasado de la epistemología occidental, Kristeva identifica positivismo con nominalismo, y atribuye al semiótico el papel de descriptor que haga ver a la sociedad "que el discurso científico no es una simbolización, que es una práctica que no refleja, sino que hace" (2001, 75). Este hacer influye en todos los discursos y es tanto justificador como provocador de acontecimientos. Baste como ejemplo el apoyo otorgado a distintas formas de esclavitud, segregación y extinción étnica por parte de teorías biológicas y racionalistas - supuestamente de base científica- a lo largo del último siglo y medio (Sánchez Arteaga, 2007).

Esta actitud positivista ante la ciencia parte de un proceso de cosificación de la misma, que deja de ser entendida como una producción cultural resultado del trabajo combinado de una sociedad. La ciencia parece entonces un espejo del mundo y la visión científica se asimila a la visión 'natural', verdadera y real. Berger y Luckmann definen este proceso de 'reificación' como "la aprehensión de los productos de la actividad humana como si fueran algo distinto de los productos humanos, como hechos de la naturaleza, como resultados de leyes cósmicas, o manifestaciones de la voluntad divina" $(1997,116)$. En este proceso se pierden la carga simbólica y la situación histórica de la ciencia. Alguno de los autores que venimos tratando tiene claras estas cuestiones. La Guía de Adams lo explica del siguiente modo:

[T]odo universo dado no es realmente una cosa en sí, sino una forma de enfocar lo que técnicamente se conoce como TCRG, o Toda Clase de Revoltijo General, que tampoco existe realmente, sino que es la suma total de todas las diversas formas de enfocarlo en el caso de que tuviese una existencia real. $(1994,48)$

En cierta manera, Benni, Adams y Dick son artífices que 'construyen' una realidad alternativa con un discurso que toma ele- 
mentos del científico (o, mejor dicho, de lo que se da por consabido como 'discurso científico') para mostrarnos la irrealidad de este discurso y, por lo tanto, la realidad de nuestro universo. Crean mundos que nos hacen pensar en la 'imposibilidad' del nuestro, y que contribuyen a que tomemos consciencia de la existencia de un nuevo mundo posible al que ya aludía Lewis (1978): el que se encuentra en el nivel de las creencias 'abiertas' de la comunidad, sobreimpreso encima del mundo actual. De la lectura de sus textos se desprende la idea de que todo intento de explicación que creemos para el mundo, todo metarrelato, no deja de ser eso, una explicación transitoria y temporal, susceptible de ser negada, discutida o desarrollada. Y la ciencia es otra explicación más: un constructo que no puede considerarse armazón definitivo para comprender la motivación de nuestra vida, universo y todo.

En esta trama de mundos y universos tenemos que volver de nuevo a Berger y Luckmann (1997) para hablar de 'universos simbólicos', productos teóricos, objetivos y sociales con una historia propia. Estos universos consisten en acumulaciones de saberes, ordenados jerárquicamente, que permiten explicar la realidad cotidiana. El universo simbólico imperante - en la actualidad y en nuestro contexto cultural, la ciencia - legitima el orden institucional y permite, a nivel individual, integrar realidades marginales. Como la realidad de los sueños o la de la literatura. Nuestra concepción del mundo queda expuesta por tanto como un constructo social y su aprehensión como tal, como una función de la socialización. La existencia de este universo simbólico en el que vivimos inmersos no es palpable, sin embargo, y tan solo adquirimos consciencia de ella cuando observamos la propia realidad desde un nuevo punto de vista. El choque de culturas o la irrupción de lo 'raro' puede tener este efecto:

Arthur sintió una tremenda emoción. Eso era exactamente lo que prometía el folleto. Ahí tenía un hombre que parecía moverse a través de alguna suerte de espacio Escher y decía cosas verdaderamente profundas sobre toda clase de cosas. 
Aunque le ponía nervioso. El anciano pasaba ahora del poste al suelo, del suelo a un poste, de poste a poste, de poste al horizonte y al revés: estaba dejando completamente en ridículo al universo espacial de Arthur.

[...]

- ¿Cómo lo ha...

- No te lo puedo decir.

- ¿Por qué no? Yo vengo de ahí.

- No puedes ver lo que yo veo porque ves lo que ves. No puedes saber lo que yo sé porque sabes lo que sabes. Lo que veo y lo que sé no pueden añadirse a lo que ves y lo que sabes porque son cosas de distinta especie. Ni tampoco puede sustituir lo que ves y lo que sabes porque eso supondría sustituirte a ti mismo. [...] Todo lo que ves, oyes o sientes de la forma que sea, es específicamente tuyo. Tú creas un universo al percibirlo, de modo que todo lo que percibes en ese universo es específicamente tuyo. (Adams, 1944, 113)

Precisamente esta idea de Berger y Luckmann explica la posición de Eco, que no pierde de vista el hecho de que el mundo actual no es sino un mundo posible más. Tampoco obvia la centralidad de la ciencia en la configuración de ese mundo posible, y deja claro que es esta el constructo cultural dominante para el lector actual cuando dice:

One can say that the fantastic property of not dying when swallowed by a beast does not hold in the 'real' world because it is inconsistent with the second principle of thermodynamics. But to judge this property as 'untrue' or 'impossible', we just refer to a system of notions, that is, to our semantic encyclopaedia.

When the medieval reader read in the Bible that Jonah was swallowed by a whale, the reader did not find this fact inconsistent with his own encyclopaedia, that is, the various Specula Mundi basically founded upon the Bible. Now, his encyclopaedia was a much a text as our own (our reasons for judging our encyclopaedia more reliable are extrasemiotic and extralogical). $(1979,222)$ 
Desde este punto de vista, lo que plantean los textos literarios que hemos comentado es una revisión del universo simbólico en el que la mayor parte de nosotros nos vemos inmersos, que está justificado principalmente por esa visión que llamamos más arriba 'positivista' de la ciencia. Al poner en cuestión la validez o actualidad de unos conocimientos dados, al mostrar sus costuras y al desvelar el hecho de que la mayoría de la sociedad — los no expertos- no somos capaces de entender las argumentaciones sobre las que se yergue nuestra concepción de la realidad, el mismo concepto de 'realidad' queda sujeto a duda. Un científico conocido de Wonko el Cuerdo, personaje de Adams, lo explica de una manera bastante irónica:

- Me temo que no puedo hacer comentarios sobre el nombre del Dios de la Lluvia en estos momentos; ahora le denominamos Metereológico Fenómeno Espontáneo Paracausal.

- ¿Puede decirnos qué significa eso?

- No estoy completamente seguro. Vamos a ser francos. Si descubrimos algo que no entendemos, nos gusta denominarlo de un modo que no se pueda entender, ni siquiera pronunciar. O sea, que si nos limitamos a permitirles que le llamen Dios de la Lluvia, ello implica que ustedes saben algo que nosotros desconocemos, y me temo que eso no podemos permitirlo.

No, primero tenemos que ponerle un nombre que sugiera que es nuestro, no de ustedes, y luego nos dedicamos a encontrar algún modo de demostrar que no es lo que ustedes dicen, sino lo que decimos nosotros. $(1988,133)$

De forma circular, El hombre en el castillo, ¡Tierra! o La guía del autoestopista galáctico parten de la construcción de universos literarios que se muestran como 'realistas' en relación con el universo o mundo actual. Pero en los mecanismos de esa síntesis se desvela el hecho de que nuestro mundo actual, el 'real', no es sino un constructo social, un universo simbólico: un mundo posible más en el que vivimos sin comprenderlo en su extensión. Con respec- 
to a estos mundos 'imposibles' que cuestionan la propia identidad, decía Eco que su efecto característico es el de producir una sensación de extrañeza lógica e incomodidad narrativa: suscitan un sentimiento de sospecha con respecto a las creencias comunes y afectan a la disposición de creer en las leyes mejor acreditadas del mundo de nuestra enciclopedia. "They undermine the world of our encyclopedia rather than build up another self-sustaining world" $(1979,234)$. En definitiva, estas obras demuestran la estrecha relación entre literatura y realidad, constatando una vez más la aserción de Mukařovský según la cual "la poesía [y, por extensión, la literatura] ejerce, mediante los individuos que crean y leen una influencia sobre la manera como la sociedad entera concibe el mundo" $(1977,200)$.

Como hemos visto, estos mundos de ciencia ficción 'raros', o pos-imposibles, tienen un efecto muy curioso. Se conforman a partir de nuestro conocimiento del mundo, dándolo como acertado y concreto, y nos muestran en última instancia cómo ese conocimiento del mundo está social e históricamente marcado. Siguiendo la trayectoria de un viaje imaginario, socavan nuestra percepción y desvelan nuestra adscripción inconsciente a concepciones asentadas sobre el valor de la tradición. Lo pos-imposible diluye la frontera divisoria entre lo posible y lo imposible abriendo las puertas a la imaginación proteica e invitando a rellenar las lagunas del conocimiento.

Estas conclusiones nos llevan a plantear nuevas preguntas para el estudio de los géneros literarios. Abren una brecha en la topografía generalmente aceptada, que distinguía claramente ciencia ficción y fantasía. Corresponden de manera indiscernible a dos modelos de mundos posibles distintos: el ficcional verosímil y el inverosímil, puesto que los autores juegan a soliviantar la ley de máximos semánticos según la cual la presencia de rasgos inverosímiles impediría la configuración de un mundo ficcional verosímil (Albaladejo, 1998; Martín-Jiménez, 2015b, §V). Por este motivo, la categoría de lo pos-imposible nos llama también a reflexionar acerca del convencionalismo de la teoría de 
géneros, en la medida en que permite la categorización de todas las obras que tratamos bajo el abrigo de la ciencia ficción solo por la manutención de unos ciertos topoi. Pues, si nos ceñimos a las definiciones expertas de 'ciencia ficción', veremos que estos textos no pertenecen exactamente al género, aunque, intuitivamente, sí lo hacen. ¿Es nuestra categorización de los géneros analítica o sintética? ¿Al aplicar los membretes genéricos a determinadas obras, estamos estudiando categorías preexistentes o creando nuevas agrupaciones? A la vista del panorama actual en los estudios de géneros literarios parece que la respuesta a estas preguntas depende de la lógica genérica que adopte el teórico (Schaeffer, 2006), es decir, en virtud del paradigma genérico escogido - en un sentido laxo del término 'paradigma' - Y estas lógicas genéricas, ya lo apuntaba Jameson, son inconmensurables (1985, 108). Alcanzar una solución a estas cuestiones, consecuencia de la proliferación de teorías genéricas inconmensurables, parece improbable: no en vano decía Kuhn que "quienes proponen los paradigmas en competencia practican sus profesiones en mundos diferentes" $(1988,233)$.

\section{Referencias bibliográficas}

Adams, D. (1988) Hasta luego, y gracias por el pescado, Barcelona, Anagrama.

Adams, D. (1994) Informe sobre la Tierra: fundamentalmente inofensiva, Barcelona, Anagrama.

Adams, D. (2003) “Is There an Artificial God?”, en Adams, D., The Salmon of Doubt, Londres, Macmillan, 126-150.

Albaladejo Mayordomo, T. (1998) Teoría de los mundos posibles y macroestructura narrativa, Alicante, Universidad de Alicante.

Benni, S. (1986) ;Tierra!, Barcelona, Anagrama.

Berger, P. L. y Luckmann, T. (1997) La construcción social de la realidad, Buenos Aires, Amorrortu.

CARrère, E. (2018) Yo estoy vivo y vosotros estáis muertos. Un viaje en la mente de Philip K. Dick, Barcelona, Anagrama. 
Dick, P. K. (1994) El hombre en el castillo, Barcelona, Minotauro. Dostoievski, F., (2001) Los hermanos Karamázov, Madrid, Cátedra.

Eco, U. (1979) "Lector in Fabula: Pragmatic Strategy in a Metanarrative Text", en Eco, U., The Role of the Reader, Bloomington, Indiana University Press, 200-260.

Eco, U. (1988) “Los mundos de la ciencia ficción”, en Eco, U., De los espejos y otros ensayos, Barcelona, Lumen, 185-192.

Feyerabend, P. (1984) Adiós a la razón, Madrid, Tecnos.

Fisher, M. (2016) Lo raro y lo espeluznante, Barcelona, Alpha Decay.

Jameson, F. (1985) The Political Unconscious. Narrative as a Socially Symbolic Act, Ithaca, Cornell University Press.

Kristeva, J. (2001) Semiótica I, Madrid, Fundamentos.

Kunn, T. S. (1988) La estructura de las revoluciones científicas, México / Madrid / Buenos Aires, Fondo de Cultura Económica.

Lem, S. (1978) Diarios de las estrellas. Viajes, Barcelona, Bruguera.

Lewis, D. (1978) "The Truth in Fiction", American Philosophical Quarterly, 15, 1, 37-46.

Martín Jiménez, A. (2015a) "A Theory of Impossible Worlds", Castilla. Estudios de Literatura, 6, 1-40.

Martín Jiménez, A. (2015b) Literatura y ficción. La ruptura de la lógica ficcional, Bern, Peter Lang.

McHale, B. (2004) Postmodernist Fiction, Londres / Nueva York, Routledge.

Mountfort, P. (2016) “The I Ching and Philip K. Dick's The Man in the High Castle", Science Fiction Studies, 43, 2, 287-309.

MuкAк̌ovsкÝ, J. (1977) Escritos de Estética y Semiótica del Arte, Barcelona, Gustavo Gili.

Putnam, H. (1984) “El significado de 'significado'”, Teorema: Revista Internacional de Filosofía, 14, 3-4, 345-406.

Rodríguez PequeÑo, J. (1997) "Mundos imposibles: ficciones posmodernas", Castilla: Estudios de Literatura, 22, 179-188. 
Rodríguez Pequeño, J. (2008) Géneros literarios y mundos posibles, Madrid, Eneida.

Ryan, M.-L. (1991) Possible Worlds, Artificial Intelligence and Narrative Theory, Indiana, University of Bloomington / Indianapolis Press.

Sánchez Arteaga, J. (2007) La razón salvaje. La lógica del dominio: tecnociencia, racismo y racionalidad, Madrid, Lengua de Trapo.

Schaefer, J.-M. (2006) ¿Qué es un género literario?, Madrid, Akal.

Suvin, D. (1984) Metamorfosis de la ciencia ficción, México D. F., Fondo de Cultura Económica.

Todorov, T. (1981) Introducción a la literatura fantástica, México D. F., Premia.

Todorov, T. (2012) Los géneros del discurso, Buenos Aires, Waldhuter Editores. 
